\title{
O IMAGINÁRIO POPULAR COMO ATRATIVO TURÍSTICO: O CASO DO SACI DE BOTUCATU/SP E DO LOBISOMEM DE JOANÓPOLIS/SP
}

\author{
Leonardo Giovane Moreira Gonçalves, Fabio Luciano Violin, Juliana Maria Vaz Pimentel \\ Universidade Estadual Paulista - UNESP, Turismo, Campus Experimental de Rosana, SP. E-mail: \\ leonardo.giovane@hotmail.com
}

\begin{abstract}
RESUMO
As inovações tecnológicas, a facilidade de acesso e o comodismo proporcionado pela internet, implicam em uma nova reestruturação dos destinos turísticos, para que tenham alguma força de estímulo. Neste êmulo, inserem-se os destinos com o desafio de modificarem-se para estimular o público. Assim, o presente artigo buscou analisar o imaginário popular como atrativo turístico, versando sobre os mitos do Lobisomem de Joanópolis/SP e do Saci em Botucatu/SP. Para tal objetivo, utilizou-se de uma pesquisa bibliográfica exploratória, em livros, sites, artigos e em outros materiais sobre a temática. Assim, tornou-se possível identificar o imaginário popular como um elemento passível da apropriação comercial e indução de fluxos turísticos e, de que forma a atividade turística faz uso desses elementos para a comercialização.

Palavras-chave: Lobisomem, Saci, Imaginário Popular, Apropriação Comercial, Atrativo Turístico.

\section{POPULAR IMAGINARY AS A TOURIST ATTRACTION: THE CASE OF SACI OF BOTUCATU/SP AND THE WEREWOLF OF JOANÓPOLIS/SP}

\begin{abstract}
Technological innovations, the ease of access and the convenience provided by the Internet, imply a new restructuring of tourist destinations, so that they have some stimulus force. In this emulator, destinations are inserted into the challenge of modifying themselves to stimulate the public. Thus, this article sought to analyze the popular imaginary as a tourist attraction, versing about the myths of the Werewolf of Joanópolis/SP and the Saci of Botucatu/SP. For this purpose, it was used for an exploratory bibliographical research, in books, websites, articles and other materials on the thematic. Thus, it has become possible to identify the popular imaginary as an element liable for commercial appropriation and induction of tourist flows and, in which way the tourist activity makes use of these elements for marketing.
\end{abstract}

Keywords: Werewolf, Saci, Popular Imaginary, Commercial Appropriation, Tourist Attraction.

\section{INTRODUÇÃO}

O avanço tecnológico forneceu ás pessoas certa mobilidade e comodidade. Serviços e produtos que outrora eram oferecidos e executados nos estabelecimentos comerciais, na atualidade podem ser adquiridos dentro de suas residência, um exemplo clássico são as compras de produtos pelas lojas virtuais presentes na internet.

Desse modo, além do grande número de concorrentes que cresce a cada ano, as empresas, em especial as do ramo turístico, têm como desafio driblar a comodidade promovida pela internet e vencer a inércia que impulsiona os consumidores a ficarem em suas residências, ofertando para tanto opções de deslocamento, lazer e turismo.

Nessa sociedade competitiva com fatores de grande de influência que interferem no macro e no microambiente empresarial, diante da recessão econômica que se verifica atualmente no 
país, as empresas necessitam de estratégias de planejamento e de alternativas inovadoras para atrair e fidelizar clientes (KOTLER, et al., 2006, p.181).

A inovação consiste na adoção de medidas criativas por parte dos gestores que podem atribuir aos lugares aspectos característicos, únicos e inconfundíveis. A autenticidade tornou-se algo em voga e, sem sombra de dúvidas, as novas correntes de fluxo turístico buscam o diferencial nos destinos, seja o único, o curioso ou o lúdico (ANSARAH, 1999, p.16).

Destarte, o presente artigo busca analisar o imaginário popular como atrativo turístico, versando sobre os mitos do Saci de Botucatu/SP e do Lobisomem de Joanópolis/SP. Com isso busca-se responder aos seguintes questionamentos: Seria um elemento da cultura do imaginário popular capaz de motivar fluxos turísticos? E se sim, de que forma o turismo se apropria desse patrimônio imaterial?

\section{METODOLOGIA}

Buscando responder os questionamentos expostos, utilizou-se como metodologia uma pesquisa bibliográfica exploratória a partir de livros, revistas e artigos científicos, que serviram de base para entender os conceitos da oferta turística, produto turístico e a dinâmica turística. Ademais, com o intuito de entender se existe um uso turístico do imaginário como e de que forma o mesmo se desenvolve, foram realizadas pesquisas exploratórias nos sites oficiais dos dois municípios paulistas, além de outros sites que discorrem sobre.

\section{RESULTADOS}

\subsection{O MITO DO SACI NO MUNICÍPIO DE BOTUCATU}

O Municipio de Botucatu/SP está situado na mesorregião de Bauru/SP, possui como municípios limítrofes: Anhembi, Bofete, Pardinho, Itatinga, Avaré, Lençóis Paulista, Pratânia, São Manuel, Dois Córregos e Santa Maria da Serra, todos esses pertencentes ao estado de São Paulo. O Municipio possui cerca de 141.032 habitantes, dispersos em uma área de $1482,874 \mathrm{~km}^{2}$. (IBGE, 2016)

A origem do mito do Saci em Botucatu se dá devido ao imaginário popular com o plano de fundo das fazendas de café, mão de obra escrava e o desenvolvimento das ferrovias. A região foi palco da expansão cafeeira e viveu desse comércio por muitas décadas, desde 1830, assim o Saci era um personagem presente na oralidade vivenciada nas fazendas de café. As estórias e aventuras do personagem folclórico eram passadas de gerações em gerações ate que com o advento da energia elétrica o mito perde força. (VIEIRA, 2009)

Depois desse período algumas pessoas começaram a discursar que "criavam" sacis em suas fazendas, fato esse que ocasionou na fundação da Associação Nacional dos Criadores de Saci (ANCS) conhecida pela figura de José Oswaldo. (MEZZENA, 2012, p. 18)

A partir da criação da Associação, o seu fundador participou de inúmeros programas na televisão aberta, como por exemplo: o programa da Ana Maria Braga, na Rede Globo e, no Programa do Jô Soares, na época no SBT, com o enfoque da mídia Botucatu passa a ser conhecida como a "Terra do Saci". (MEZZENA, 2012, p. 19)

Com o enfoque da mídia o Saci passa a ser apropriado pelo comércio e cria-se o "Festival Nacional do Saci", segundo Menezza (2012):

[...] Festival Nacional do Saci, é uma festa que tem incrementado o turismo local. Os artesãos mobilizaram-se para se especializarem no tema saci e hoje em dia suas obras de arte são conhecidas não só nas cidades da região como também na Europa. A culinária local tem se profissionalizado em alimentos naturais que seriam do agrado do saci e há também uma forte exploração do ecoturismo para atrair visitantes à cidade, devido ao potencial ecológico do local. (MENEZZA, 2012, p. 19) 
Por meio da citação é possível observar que algo que pertencia ao imaginário local tornouse um elemento cultural atrativo por meio de uma estratégica de mercado, neste caso o Evento. $\mathrm{E}$ a criação desse evento trouxe a demanda turística e aprimorou a oferta, uma vez que segundo a autora novas peças artesanais e alimentos foram criados para celebrar o personagem.

Insere-se a globalização como fator que determina as novas relações, Segundo Vieira (2009, p. 116) "as transformações culturais e tecnológicas advindas da globalização influenciam consideravelmente as narrativas sobre o Saci, dando-lhes novas formas, sentidos, valores e modos de existência na sociedade". Destarte pode-se entender a cultura como um elemento mutável e que como observado passa a ser apropriada comercialmente de acordo com as novas tendências e necessidades da sociedade atual.

\subsection{O MITO DO LOBISOMEM NA ESTÂNCIA TURÍSTICA DE JOANÓPOLIS}

A Estância Turística de Joanópolis está situada nos conformes das Serra da Mantiqueira, possui como municípios limítrofes Extrema/MG, Itapeva/MG e Piracaia/SP. O município faz parte da Mesorregião Macro Metropolitana Paulista e da Microrregião de Bragança Paulista (BRASIL, 2012).

Sendo um município de porte pequeno de população média de 11.768 habitantes (em 2010) e, segundo estimativas do Instituto Brasileiro de Geografia e Estatística (IBGE), 12.725 habitantes em 2015 (IBGE, 2015). Sua economia tem base na pecuária, produção agrícola, comércio e serviços, bem como na atividade turística. Por conta de suas sinuosas ruas, arquitetura das casas, belezas paisagísticas, grande biodiversidade, aspecto histórico, patrimônio material e imaterial, no dia 23 de janeiro de 2001 o município foi elevado a Estância Turística.

A caracterização do município de Joanópolis como "capital do Lobisomem" surgiu em 1983 com uma estudante da Escola de Folclore de São Paulo, Maria do Rosário de Souza Tavares de Lima, pertencente a uma família tradicional de Joanópolis, que escreveu sobre o Lobisomem, em livro publicado em 2004, intitulado "Lobisomem: Assombração e Realidade" (PAIVA JÚNIOR; GODOY, 2000, p. 74).

A pesquisa ganhou grande notoriedade na época, trazendo olhares para os mistérios de Joanópolis. Segundo relatos, esse "lado tão especial atraiu mais olhares curiosos. E ainda na década 80, Joanópolis foi apontada como a Capital Nacional do Lobisomem. O Jornal "O Estado de S. Paulo" sugeriu a Joanópolis esse título que na época recaiu sobre a cidade como bomba" (PAIVA JÚNIOR; GODOY, 2000, p.76).

Depois de alguns anos da publicação da pesquisa, os comentários sobre a terra do lobisomem diminuíram, mas Paiva Júnior e Godoy (2000, p.78) ressaltam que "o lobisomem ressurgiu em Joanópolis, numa época, num outro tempo. Mais de dez anos depois, em 1998, um comercial de televisão trouxe o lobisomem de volta". O comercial foi da rede de fast food, que tinha como tema o Lobisomem e foi gravado na própria cidade.

Após a veiculação do comercial foi fundada em 22 de agosto de 1998 a Associação dos Criadores de Lobisomem- $A C L$, que tem como intuito disseminar e perpetuar a imagem de Joanópolis como "A Capital do Lobisomem". Paiva Júnior e Godoy (2000) apresentam em seu livro "Lobisomem existe!", por meio de uma série de entrevistas com joanópolenses, que:

Num estalo o mito rompeu fronteiras. Foi festejado no único clube de Joanópolis, ganhou coluna de jornal e um programa de rádio na cidade vizinha, Piracaia. Em um dos programas de rádio, um ouvinte chegou a denunciar que certa pessoa da cidade virava lobisomem. A audiência aumentava cada vez mais e o bicho cresceu na consideração do povo. $O$ lobisomem, criatura secular, se transformou em um ser multimídia. Tem até site na Internet! (PAIVA JÚNIOR; GODOY, 2000, p.81) 
A partir disso é possível observar a utilização da imagem do lobisomem com finalidades comerciais, ou seja, utilização do mito como um chamariz para o comércio e indução de turistas. Essa atratividade se dá por meio de estórias, insumos, camisetas, canecas, artesanato e outros objetos que possam ser comercializados fazendo referencia a temática. Esta concepção pode ser entendida por meio de Lima (2004) que disserta:

Na ação publicitária da cultura de mídia explora-se o impacto da mídia no consumidor em potencial. Determina marca de carro, talão de cheques, uísque, refrigerante, cosméticos, alimento, cigarro, calça de brim, material de limpeza ou qualquer outro produto, assumem feições de mito, com propalados efeitos mágicos, capazes de proporcionar uma vida melhor, alegria, saúde, juventude, poder, projeção social, destaque pessoal, felicidade. São os mitos modernos, da cultura mercantil, tão objetos de culto quanto todos os outros. (LIMA, 2004, p. 14)

Portanto, a apropriação do mito do lobisomem, em especial, possuiu e possui inúmeras vertentes de utilização para usufruto turístico. Contudo, ressalta-se que o mito do lobisomem possui um lado obscuro, dado os hábitos e o fadário do próprio personagem e, assim, para desconstruir as características maléficas do personagem, a Associação dos Criadores de Lobisomem- ACL desenvolveram uma imagem positiva do lobisomem. Em seu livro Paiva Júnior e Godoy (2000, p. 90) realizam uma entrevista com o vice-presidente da ACL que exemplifica que "precisamos 'criar' um lobisomem bonzinho. Mudar um pouco essa cara de que lobisomem come crianças, rola em estrume de galinha. Vamos criar um lobisomem moderno, diferente".

E por meio desta "metamorfose", a imagem do Lobisomem ganhou público, tornou-se atrativa e foi apropriada como uma temática indutora de turistas para estabelecimentos e, além disso, para o município como um todo. Giovane $(2015$, p. 8) observa que "[...] ao andar pelas ruas da pequena Joanópolis é possível ver vários desses lobisomens espalhados pelo comércio, um mais criativo do que o outro, que convidam os visitantes a tirar uma foto".

Em seu texto Cassalho (2015) argumenta que:

Hoje em dia, o lobisomem pode ser considerado o carro chefe na divulgação do turismo da cidade, aproveitando o folclore e mostrando as belezas naturais que o município encerra. No mês de agosto acontecia a Trilha do Lobisomem, ocasião em que dezenas de jeepeiros percorriam a madrugada joanopolense na esperança de ver o bicho. Além disso, as pessoas estão descobrindo os mistérios da lua cheia, ou seja, estão reatando com seu imaginário, buscando ouvir e relembrar as histórias de assombração e outros contos, pacientemente contados pelas pessoas mais antigas da família ou da comunidade. (CASSALHO, 2015)

A atratividade municipal, quando refere-se ao mito do Lobisomem, está atrelada aos estabelecimentos comerciais que se apropriaram do mito para o comércio, reforçando a própria localidade como um cenário possível para disseminação do mito e em consequência o status, ou seja, o reconhecimento do lugar como "A Capital do Lobisomem".

\section{DISCUSSÃO}

\subsection{A ATRATIVIDADE TURÍSTICA}

Quando menciona-se o caráter atrativo da atividade turística suscita-se inúmeros conceitos e divisões na academia. Sendo assim, o produto turístico também possui diferentes formulações, divisões e interpretações. Esse pode ser entendido também como oferta turística, que por sua vez se divide em original e agregada, bem como os atrativos turísticos, recursos turísticos e os equipamentos e serviços turísticos. 
Braga (2007) menciona que atrativo turístico é “[...] um elemento que efetivamente recebe visitantes e tem estrutura para propiciar uma experiência turística. Nesse caso, o recurso foi adaptado para tornar-se atrativo [...]". O atrativo turístico diverge do recurso turístico, uma vez que os "recursos turísticos são os elementos de uma localização que tem potencialidade para tornar-se atrativo turístico; ou seja, constitui-se na matéria-prima do turismo [...]" (BRAGA, 2007, p.79).

Desse modo, a concepção de equipamentos e serviços turísticos por sua vez pode ser compreendida nos seguintes termos:

Os equipamentos e serviços turísticos formam o conjunto de empreendimentos e negócios relacionados ao turismo, direta ou indiretamente, tais como hospedagem, alimentação, entretenimento, agenciamento, trabalho de guias, locações de meios de transporte, locais para eventos e muitos outros (BRAGA, 2007, p.79).

Dias (2003, p.203) menciona que os recursos e os atrativos turísticos "constituem um dos fatores determinantes para o desenvolvimento da atividade turística, e que de um modo geral motivam o indivíduo a viajar [...]". Observa-se, assim, que os mesmos são elementos indutores de turistas, contudo é possível aferir que os equipamentos e serviços turísticos também podem ter a função de atrair turistas, uma vez que é possível o espaço comercial absorver o caráter de atrativo turístico.

Esta concepção pode ser embasada sendo que "o atrativo turístico possui, via de regra, maior valor quanto mais acentuado for seu caráter diferencial. O turista procura sempre aquilo que é diferente de seu cotidiano. Assim, aquele atrativo único, sem outros semelhantes, possui maior valor para o turista" (ROSE, 2002, p.47). Nesse sentido insere-se a singularidade dos destinos como chamariz de turistas.

Enfatizam-se os destinos como responsáveis por ofertar experiências à demanda turística. Contudo, na era globalizada de culturas plurais, esses destinos necessitam de características diferenciadas, capazes de aguçar a curiosidade humana. Ateljevic e Li (in: ATELJEVIC, PAGE; ALMEIDA, 2011, p.6) mencionam que "[...] compreender a curiosidade humana é, na verdade, uma precondição essencial para o entendimento do empreendedorismo turístico. Esse utiliza a manipulação da curiosidade humana para fins comerciais, e isto é fundamental para a habilidade empreendedora [...]".

Assim, o comportamento do consumidor no turismo visa a escolha de produtos diferenciados, lugares que possuam características próprias, que inspirem sonhos, ou seja, trabalhem com o lado lúdico humano. Dado que "muitos exemplos provam que a curiosidade humana, certamente, é o pilar central de muitos produtos e serviços turísticos. O produto turístico pode ser quase tudo que provoque curiosidade humana, desde que seja nomeado, descrito, precificado e oferecido [...]" (ATELJEVIC; LI, IN: ATELJEVIC, PAGE: ALMEIDA, 2011, p.6). Deste modo, entende-se o imaginário popular como recurso passível de se tornar um produto turístico uma vez formatado para determinada oferta turística.

\section{CONCLUSÃO}

A crise financeira da atualidade, determinante da concorrência entre destinos, da desvalorização da moeda nacional e dos novos gostos dos turistas é um fator que necessita ser analisado na formatação de novos destinos turísticos, bem como sua oferta e demanda.

Por meio desse trabalho foi possível solucionar os dois questionamentos iniciais, sendo o primeiro: Seria um elemento da cultura do imaginário popular capaz de motivar fluxos turísticos? A resposta foi claramente positiva, pois a partir do momento que existe um recurso (imaginário) e o mesmo passa por uma adaptação para o comércio é culminante na geração de fluxos turísticos. No entanto observou-se que os recursos isolados, ou em outras palavras, as estórias somente 
presentes no imaginário popular, sem nenhuma formatação, não são capazes de gerar fluxos turísticos, ou seja, o imaginário local só se torna atrativo quando o mesmo é trabalhado e se transforma em produto turístico.

É nessa conjuntura que se responde a segunda pergunta: de que forma o turismo se apropria desse patrimônio imaterial? Como visto o turismo se apropriou desse patrimônio por meio da culinária, artesanato, musicas cantigas, apresentações e eventos. Não obstante, em cada cidade, a apropriação comercial se desenvolveu de determinada forma, mas em ambas o sucesso da marca "Capital do Lobisomem" ou "Terra do Saci" só foi introduzida quando a mídia de massa enxergou o imaginário como potencial. Assim, ressalta-se o papel da mídia na formação dos destinos turísticos e, sobretudo na formação da percepção humana.

Outro fator que deve ser salientado é que o uso do Lobisomem e do Saci, e outros personagens, como atrativos turísticos auxiliam na disseminação e perpetuação do mito, bem como mantendo vivos os mitos e lendas do folclore brasileiro e impedindo assim o efeito acultural que se visualiza na atualidade.

Nesse êmulo conclui-se que o patrimônio imaterial, a cultura do imaginário, tem potencial de promover a visitação turística, desde que o mesmo seja estruturado e sistematizado, pois sem esse planejamento não se torna possível à visitação e tampouco cria o desejo do conhecer nos viajantes. Acrescenta-se que o planejamento da apropriação comercial do imaginário popular deve-se ser pensado de acordo com os princípios da sustentabilidade, assim prezando pelo bem estar de todos os envolvidos.

\section{REFERÊNCIAS BIBLIOGRÁFICAS}

ATELEJEVIC, J; LI, L. Empreendedorismo turístico: conceitos e ideias. In: ATELEJEVIC, J; PAGE, S;

ALMEIDA, M. V. de. Turismo e Empreendedorismo. Rio de Janeiro: Elsevier, 2011.

BRASIL, C. Município de Joanópolis. Cidade Brasil. Disponível em< http://www.cidadebrasil.com.br/municipio-joanopolis.html> Acesso em: 29 de nov, 2015.

BRAGA, D. C. Planejamento turístico: teoria e prática. Rio de Janeiro: Elsevier, 2007.

CASSALHO, V. O Lobisomem. Estância Turística de Joanópolis. Disponível em <http://www.joanopolis.com.br/o-lobisomem.html> Acesso em: 29 de nov, 2015.

DIAS, R. Planejamento do turismo: política e desenvolvimento do turismo no Brasil. São Paulo: Atlas, 2003.

GIOVANE, L. Lobisomem, mito e comércio. Jornal O Registro: Sul de Minas e Região Bragantina. Extrema/MG: 28 de mar., 8-8, 2015.

IBGE. São Paulo- Joanópolis. Instituto Brasileiro de Geografia e Estatística. Disponível em< http://www.cidades.ibge.gov.br/xtras/perfil.php?lang=\&codmun=352550\&search=sao-paulo|joan opolis|infograficos:-informacoes-completas> Acesso em: 29 de nov, 2015.

IBGE. São Paulo- Botucatu. Instituto Brasileiro de Geografia e Estatística. Disponível em < http://cidades.ibge.gov.br/xtras/perfil.php?lang=\&codmun=350750\&search=sao-paulo> Acesso em: 06 de ago, 2017. 
KOTLER, P; et al. Marketing de lugares: como conquistar crescimento de longo prazo na América Latina e no Caribe. São Paulo: Prentice Hall, 2006.

LIMA, M. do R. de S. T. de. Lobisomem: assombração e realidade. 2. Ed. São Paulo, 2004.

MENEZZA, A. C. Saci: cultura, superstição ou produto cultural? Trabalho de conclusão do curso de Gestão de Projetos Culturais e Organização de Eventos. CELACC/ECA-USP, 2012.

PAIVA JUNIOR; GODOY, S. Lobisomem Existe! Campinas, 2000.

ROSE, A. T. de. Turismo planejamento e marketing. Barueri/SP: Manole, 2002.

VIEIRA, M. de F. O Saci da tradição local no contexto da mundialização e da diversidade cultural. São Paulo. $167 \mathrm{fl}$. Tese (Doutorado) - Faculdade de Filosofia, Letras e Ciências Humanas, Universidade de São Paulo, 2009. 